\title{
Increasing Draining Capacity for Overloaded Sewers During Flooding by Means of Polymer Addition
}

\author{
Sattaya Yimprasert ${ }^{1, a}$, Ananchai Ukaew ${ }^{1, b}$ \\ ${ }^{1}$ Mechanical Engineering Department, Faculty of Engineering, Naresuan University, Thailand \\ a Sattaya3210@gmail.com, bananchaiu@nu.ac.th
}

Keywords: Polymer additives, Draining capacity, Drag reduction, Pipe flow.

\begin{abstract}
The maximum limit of water storage capacity in sewers and storm drains depends on the draining capacity of the sewer or drain. When the draining capacity is exceeded, this results in the overloading of the sewer capacity, causing flooding. This moment, which is called the "choking" phenomenon. Therefore, draining capacity will decrease, and flooding can occur in a short period of time. The purpose of the current research was to examine this phenomenon by determining the correlation between draining capacity and water storage levels in the experimental situation. The experiments were based on original techniques published in 1949 [1,2] which demonstrated an increase in the flow rate in a pipe by adding polymer solution into the fluid in a turbulent flow; this has been termed the "Drag Reduction Effect". The experiments demonstrated that the addition of the polymer solution proved to reduce the drag between the fluid and the pipe wall, and that the overloaded sewer effect can be relieved by means of polymer addition into the draining system, which enhances draining capacity during flooding situation, To conduct the experiment, an acrylic tank with a capacity of 65 litres was prepared to simulate a flooding area. Three different sizes of polyvinyl chloride (PVC) pipe (10, 18 and 20 millimeters) were used as a test section to simulate a sewer pipe. The experiment was conducted by dosing a gravity pipe flow system with Polyacrylamide (PAM), known as anionic polymer, which is normally employed in wastewater treatment processes, at different concentrations $(0,10,30,50,100 \mathrm{wppm}$ (part per million by weight), The results of the experiment indicate that a suitable amount of polymer addition can increase maximum enhancement of draining capacity up to $13 \%$ and increase maximum flow rate up to $12 \%$. It was also observed that the increased flow rates resulting from the drag reduction phenomenon occurred as an effect of the type of polymer and the concentration of the polymer.
\end{abstract}

\section{Introduction}

Worldwide it appears that the weather is changing, apparently due to global warming. Environmental aspects such as deforestation also contribute to the problem of water volume and flow. Thailand has been directly affected by climate change, and the volume of water in the main rivers of Thailand is subject to flash flooding; a common phenomenon. Significant damage occurs in many provinces of Thailand annually due to floods and water run-off especially after storms, which can be sudden and violent and bring overwhelming rain downpours. In 2011 damage from these weather and flooding conditions was about 1.4 billion Baht [1].

There are many aspects that exacerbate the flooding situation. For example where the landscape is basically a basin with surrounding high ground being the watershed; problems with the design of draining systems; and of importance is the mismatch between between water storing capacity and draining capacity of sewers in particular areas. When draining capacity is exceeded, this will result in over-loading the capacity of the sewer. This is called the "choking" phenomenon which reduces draining capacity, and consequently increases flooding.

From previous studies, flow rate capacity in a pipe can be increased by adding a polymer solution into the fluid flow in turbulent conditions. This has the effect of decreasing the friction between the fluid and the pipe wall, a situation termed the "Drag Reduction effect", first observed 
in 1949 [2], now known as Tom's Drag Reduction Effect. In 1978 Maksimovic [3] studied the choking phenomenon in a sewer system by using short diversion tunnels. The tunnels were between 2 and $10 \mathrm{~m}$ in diameter and from 12 to 100 meters in length. Figs.1a and $1 \mathrm{~b}$ show the discharge characteristics for culverts. Fig.1a shows the flow characteristics in a "drowned" pipe; i.e. water level z. Note that if the pipe is not full, or "drowned', as illustrated, the addition of polymers has no effect. Fig.1b shows the tunnel characteristics curves and shows how the drowning of the tunnel inlet, represented by the movement of the operating point from curve I to curve II (Zone A to Zone B) may lead to a rapid increase in the upstream water level if the discharge continues to increase (that is when the choking phenomenon occurs). This then may lead to flooding. However if polymer injection is commenced when this transition point is reached, the operating point will continue along curve I until it reaches the polymer characteristic curve III. Maksimovic's research determined that an extra $20-30 \%$ of discharge capacity can be obtained by using polymer injection, by reason of the discharge capacity being increased due to the Drag Reduction Effect; the reduction of the friction between the fluid and the pipe wall.
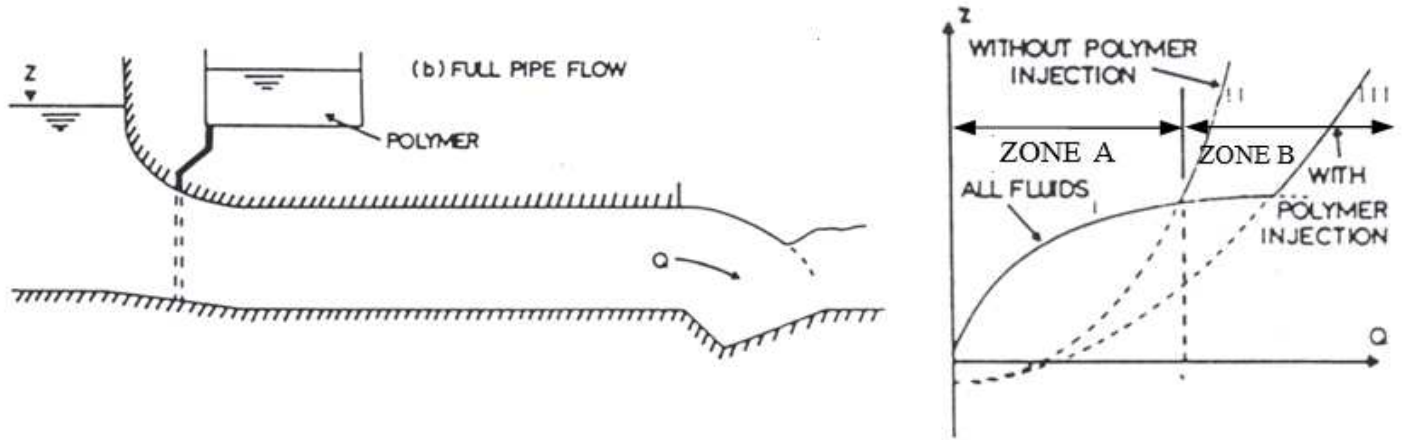

Fig.1 Discharge capacity of diversion tunnels and culverts both with polymer injection.

Further research, in 1979 by Derick C. and Logie K. [4] studied the use of polymers in sewer systems. They installed a polymer injection system in a sewer pipe with diameter $305 \mathrm{~mm}$. The polymer used was Polyox WAR-301 at a concentration of 15-40 wppm. The results of the experiment demonstrated that the injection of a polymer solution can increase fluid flow by five times the flow under normal conditions.

For the current research, we have been motivated by the findings of the previous researchers cited. The purpose of this research is therefore to study the relationship between draining capacity and water storing levels. In addition, our purpose is to study and demonstrate that the overloaded sewer effect can be relieved by means of polymer addition into the draining system to enhance draining capacity.

It is felt that this research can have important effects if it can then be transferred to large scale water drainage situtations, alleviating the damaging flooding problems that can occur, and making signficant savings for the economy by flood mitigation and alleviation.

\section{Overview of the experiment}

\section{Experimental Apparatus}

Fig. 2 shows a schematic diagram of the experimental apparatus. The flow system consists of an open-circuit water system having an acrylic tank with a capacity of 65 litres, prepared to simulate a flooding area. Polyvinyl chloride (PVC) pipe of sizes 10, 18 and $20 \mathrm{~mm}$. diameter, and $4 \mathrm{~m}$ in length, were used as a test section to simulate a sewer pipe. Plastic storage tanks with capacities of 100, 150 and 200 litres were used to fill the acrylic tank. The weight of the water flowing into the 
system was measured at the start as control. The system functioned by gravity flow). The temperature of the flowing fluid was kept stable at $25 \pm 1^{\circ} \mathrm{C}$ during the experiment.

In this experiment the anionic polymer named "Polyacrylamide (PAM)" was used, which is normally employed in the wastewater treatment process. The polymer was added to the gravity pipe flow system at different concentration; 0, 10, 30, 50, 100 wppm (part per million by weight). Polyacrylamide has a molecular weight of $10-25 \times 10^{6} \mathrm{~g} / \mathrm{Mol}$. And a half-life of $10 \mathrm{hrs}$.[5].

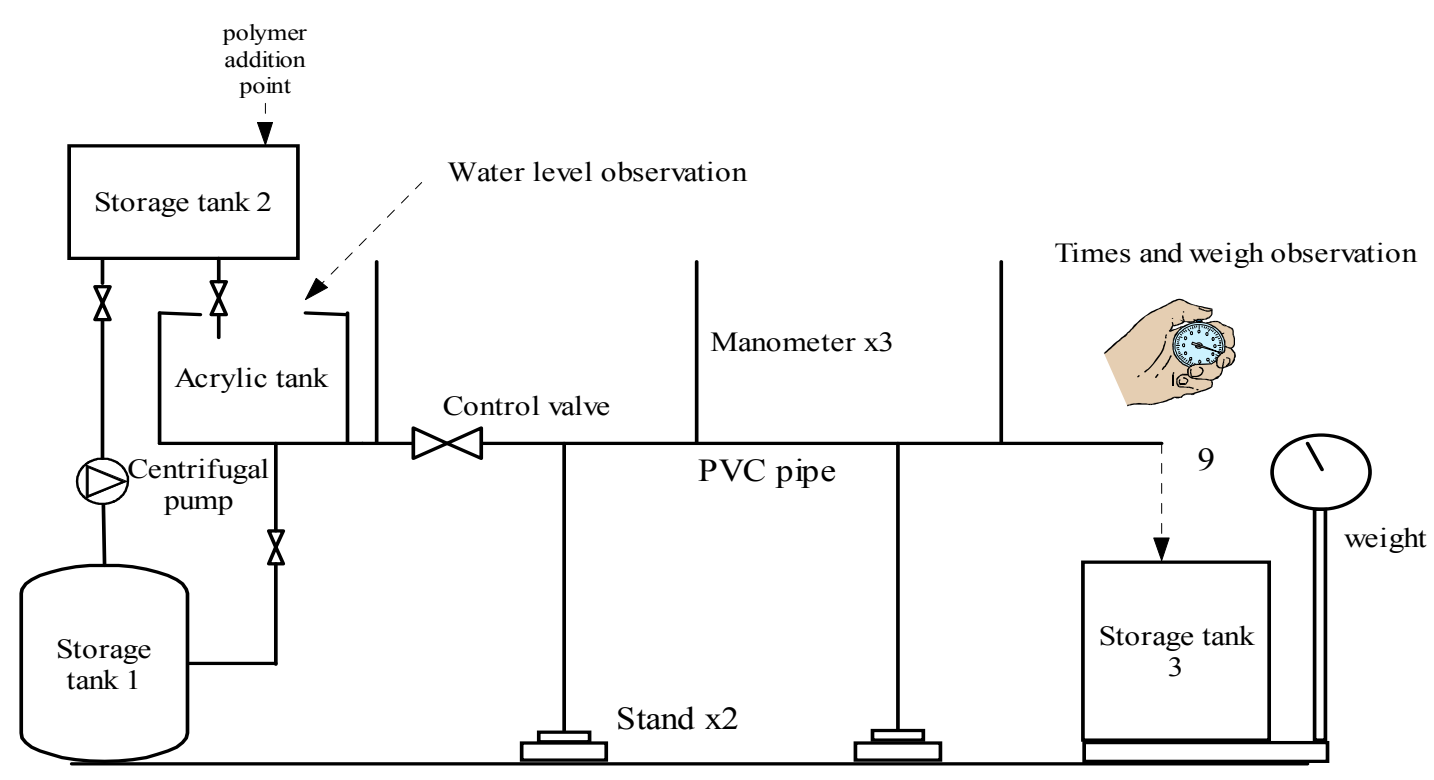

Fig. 2 Experiment apparatus

The following process was carried out during the experiment. First, the acrylic tank was filled with a given level of water. A measured concentration of polymer was added. The control valve was then opened and the water flowed into Storage Tank 3. The water pressure of the flow was measured by the manometer. Three manometers were used, measuring pressure at a point before the control valve, and at 1 metre and 2 metres after the control valve. The water inflow into Storage Tank 3 was weighed and this was used to calculate flow rate, together with time measured using a stop watch. The control valve was closed when the weight of water in Storage Tank 3 reached 30 $\mathrm{kgs}$, and the time was stopped at that point simultaneously.

This cycle of processing was done using water levels of $10 \mathrm{~cm}$ to $90 \mathrm{cms}$, with an increment of 5 cms each time. Each water level had polymer added in a varying concentration. Each water level / polymer concentration pairing was tested 3 times.

At each water level, the concentration of polymer was tested at 0 wppm, $10 \mathrm{wppm}, 30 \mathrm{wppm}, 50$ wppm and $100 \mathrm{wppm}$. So, for example, at a water level of $10 \mathrm{cms}$, measurements were taken 3 times with no polymer added, 3 times with $10 \mathrm{wppm}$ polymer added, 3 times with 30 wppm added, 3 times with 50 wppm added and 3 times with 100 wppm added.

The flow rate of water in a pipe can be calculated by the following equation $[6,7]$.

$$
Q=\rho A v
$$


Where $\mathrm{Q}$ and $\mathrm{v}$ are the flow rate and velocity in the pipe respectively. We can therefore know the flow rate and flow velocity in the pipe, using the experimental results described above, by calculating with Eq. (1).

Major loss $\left(\mathrm{h}_{\mathrm{f}}\right)$ by friction factor in the pipe is defined by following The Darcy Eq. (2) and The Energy equation Eq. (3) $[6,8,9]$.

$$
\begin{aligned}
& h_{f}=f \frac{L V^{2}}{D 2 g} \\
& h_{f}=\frac{P_{1}-P_{2}}{\gamma}+\left(Z_{1}-Z_{2}\right)
\end{aligned}
$$

Where $f$ and $\gamma$ are the friction factors in the pipe and the specific weight of the water, the friction factor (f) is the main data we wanted to observe.

The percentage increase of flow rate is defined by following Eq. (4) [10].

$$
\mathrm{Q} \%=\left(\frac{\mathrm{Q}_{\mathrm{p}}-\mathrm{Q}_{\mathrm{w}}}{\mathrm{Q}_{\mathrm{p}}}\right) \times 100
$$

Where $\mathrm{Q}_{\mathrm{p}}$ is the flow rate with polymer and $\mathrm{Q}_{\mathrm{w}}$ is the flow rate with polymer added, by mass $(\mathrm{kg} / \mathrm{s})$ obtained at the same Reynolds number value. In this study Reynolds number was set between 5,000 to 25,000 .

Flow rate in the pipe, as calculated using Eq.4, showed an increase due to the Drag Reduction Effect of adding the polymer. With a decrease in the friction factor, the flow rate in the pipe increased. However, the theory of the Drag Reduction Effect in pipes is not clear; there are many aspects of the study of fluids to be further explained, especially turbulence in pipe flow. We cannot predict the phenomenon of turbulent flow with accuracy. There are, however, three theories purporting to explain the phenomenon. Each of these theories focus on molecular polymer dynamics in turbulent flow at the pipe wall (turbulent boundary layer). The first theory presented by Lumley [11] focuses on elasticity of polymer molecules when it extends inside pipe flow and prevents eddies from occuring, which decreases energy dissipation at the pipe wall. The second theory presented by White M.C and Mungal M.G. [10] focuses on the elasticity of polymer molecules when it extends in streaks line way inside pipe flow, which decreases the radiusmomentum energy dissipation into the pipe wall. The third theory presented by Sellin R.H. [2] explains that these polymers have an effect on the energy balance between turbulence production and dissipation due to the elastic properties of the macromolecules of the polymer solution which seem as spring to store energy before dissipation into the pipe wall.

\section{Results and discussion}

1. Choking phenomenon in Pipes

Fig. 3 shows the experimental average flow rate of pure water in a pipe in the relationship between flow rate in kilograms per second units (x axis), and the level of water in centimetre units 
(y axis). We analyzed our data by using Numerical Curve fitting in the exponential function [12], resulting in a new equation.

$$
\mathrm{Z}=6.36 \mathrm{e}^{8.976 \mathrm{Q}}
$$

$\mathrm{Z}$ is the level of water and $\mathrm{Q}$ is the flow rate of a pipe. To explain the relationship of the flow rate in a pipe and the level of water we simulated a sewer pipe and water storage. Eq. (5), derived from our hypothesis if draining capacity is exceeded, shows the point of choking which will result in the over-loaded capacity of the sewer. We used the measurments for each $0.5 \mathrm{~kg} / \mathrm{s}$ of flow rate, until we found the level of water at which the water levels abruptly starts to increase. Fig.3 illustrates that the flow rate in the pipe starts to abruptly change at around $0.45 \mathrm{kgs} / \mathrm{sec}$. to 0.5 $\mathrm{kgs} / \mathrm{sec}$, and the water level increases from $270 \mathrm{~cm}$ to $500 \mathrm{~cm}$ very quickly. This situation is called the Choking Phenomenon in the pipe which explains rapid change in the water level in a short period of time. At the same time, the flow rate in the pipe decreases [3], and flooding will occur.

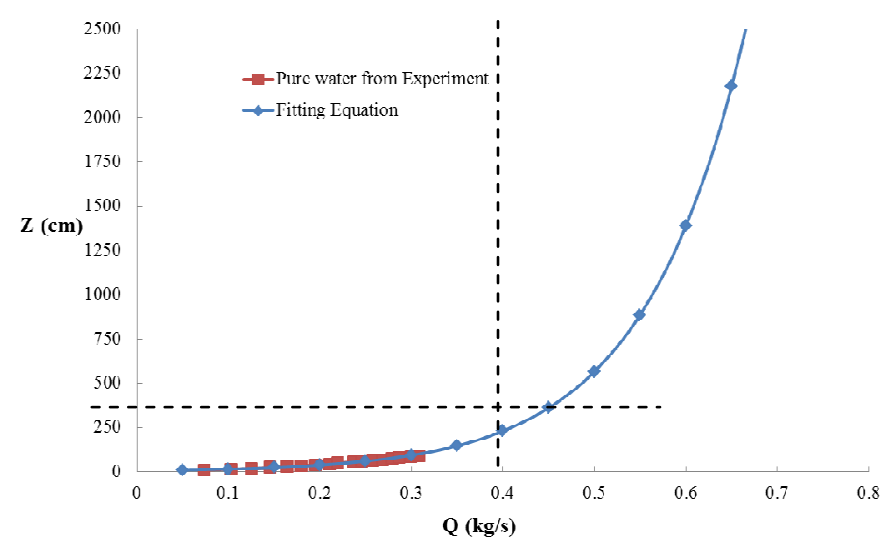

Fig. 3 Flow rate of pure water in pipe and level of water

\section{Enhancement of draining capacity by polymer addition}

We have known that choking can be occur in any pipe system if the draining capacity is exceeded, and this is the main cause of the flooding situation. From the Drag Reduction Effect study, an increase in the flow rate of a pipe in turbulent conditions occurs when polymers are added.

In this research, we investigated the mitigation of the choking phenomenon by adding Polyacrylamide into the system, at varying concentrations of 10, 30, 50 to $100 \mathrm{wppm}$. The results are shown in Fig. 4 where the $\mathrm{x}$-axis is the flow rate in pipe and the y-axis is the level of water in the acrylic tank. The graph shows the Drag Reduction Effect from the moment the polymer was added. The increase in flow rate occurred immediately, depending on the polymer concentration. From this study we found a maximum enhancement of capacity increase of $13 \%$ when compared with pure water without polymer added. 


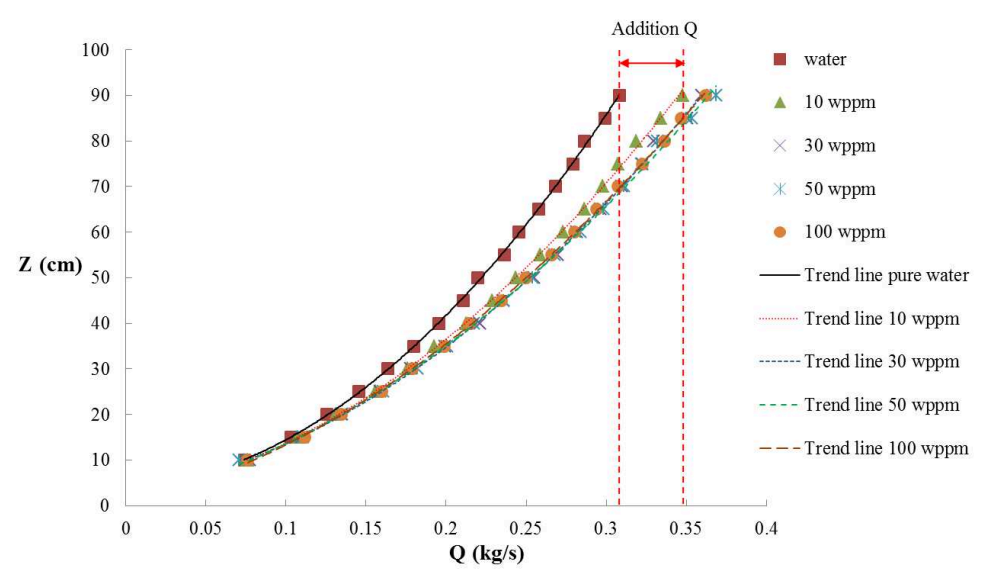

Fig.4 Flow rate of water in pipe and level of water where using polymer in different concentration.

Enhancement of capacity increasing because flow rate in pipe also increase by polymer addition, from Fig. 5 show relationship between Reynolds number in X-axis and Percentage of flow rate in pipe in y-axis, the result of experiment same as Drag reduction theory by flow in pipe rank of Reynolds number is 5000 to 40000 this means turbulent condition, then polymer addition can increase percentage of flow rate in rank 5 to $20 \%$ at concentration 10, 30, 50 and $100 \mathrm{wppm}$, finally polymer can make maximum average of flow rate $(\mathrm{Q} \%)$ at $9,13,13$ and $12 \%$ compare with pure water, data show in Table 1, therefore from observation the data in concentration 30, 50 and 100 wppm, percentage of flow rate in pipe are closely and all trend line of flow rate percentage it seem to grow up relate with Reynolds number increase.

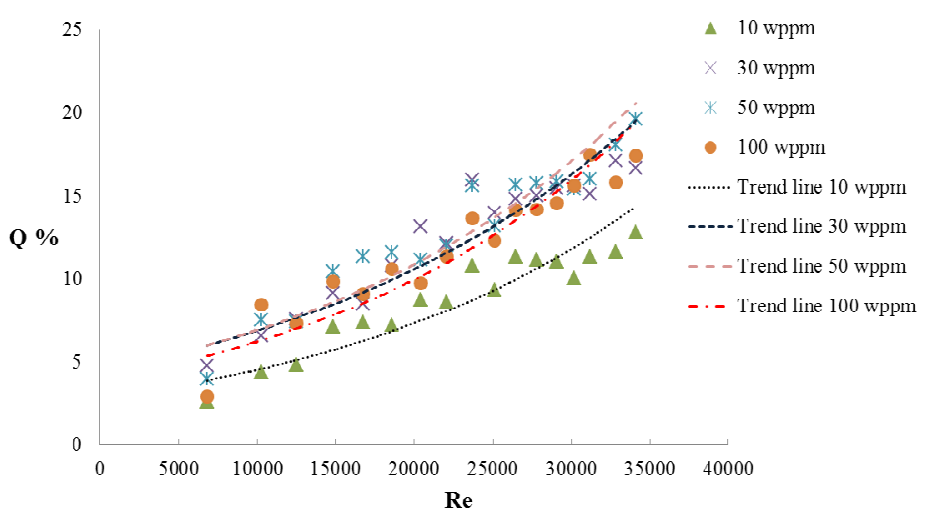

Fig.5 Percentage of Flow rate in pipe when using polymer in different concentration and Reynolds number.

Table 1 Polymer concentration and maximum flow rate in the experiment.

\begin{tabular}{|c|c|}
\hline Polymer concentration (wppm) & $\begin{array}{c}\text { Enhancement of draining capacity } \\
(\%)\end{array}$ \\
\hline 10 & 9 \\
\hline 30 & 13 \\
\hline 50 & 13 \\
\hline 100 & 12 \\
\hline Mean of all concentrations & 12 \\
\hline
\end{tabular}


The performance of the Drag Reduction Effect does depend on the type of polymer and the concentration used. The physics of polymers makes it soluble, molecular sharp is a straight line and it has short branches and a molecular weight $\left(\mathrm{M}_{\mathrm{w}}\right)$ greater than $10^{6} \mathrm{~g} / \mathrm{mol}[2]$. Table 1 shows the percentage increase if flow through the pipe at a range of polymer concentrations.

From the calculations illustrated in Fig.4, we defined the hypothesis trend line of experiment data as an exponential function. We then analyzed our data by curve fitting technique using the exponential function [12], to find the relationship between flow rate in a pipe and level of water. The relationship is shown in Table 2 as R-Square ranking which confirms the equation.

Table 2 Equation of flow rate in pipe and level of water by Curve fitting solution in different concentrations.

\begin{tabular}{|c|c|c|}
\hline Polymer concentration (wppm) & $\begin{array}{c}\text { Fitting } \\
\text { Equation }\end{array}$ & R-Square $\left(\mathrm{R}^{2}\right)$ \\
\hline Pure water & $\mathrm{Z}=6.363 \mathrm{e}^{8.976 \mathrm{Q}}$ & $\mathrm{R}^{2}=0.982$ \\
\hline 10 & $\mathrm{Z}=7.045 \mathrm{e}^{7.745 \mathrm{Q}}$ & $\mathrm{R}^{2}=0.978$ \\
\hline 30 & $\mathrm{Z}=7.521 \mathrm{e}^{7.352 \mathrm{Q}}$ & $\mathrm{R}^{2}=0.977$ \\
\hline 50 & $\mathrm{Z}=7.461 \mathrm{e}^{7.208 \mathrm{Q}}$ & $\mathrm{R}^{2}=0.977$ \\
\hline 100 & $\mathrm{Z}=7.322 \mathrm{e}^{7.342 \mathrm{Q}}$ & $\mathrm{R}^{2}=0.973$ \\
\hline
\end{tabular}

$\mathrm{Z}$ is level of water in acrylic tank (cm)

$\mathrm{Q}$ is flow rate in pipe $(\mathrm{kg} / \mathrm{s})$

To confirm the point of Relationship in Table 2, Fig. 6 was prepared in a graph of flow rate in a pipe and level of water ( $\mathrm{x}$ and $\mathrm{y}$ axis) by defining increase the flow rate every $0.05 \mathrm{~kg} / \mathrm{s}$ for finding the point of choking phenomenon, in Fig. 6 we found that point start around 0.4 to $0.65 \mathrm{~kg} / \mathrm{s} \mathrm{by}$ observing sharp of trend line change immediately, the choking situation make pipe system running in low performance that the system use to be, and in real place this phenomenon will make flooding in those areas, then when we using polymer solution in the system from Fig.6, we can increase flow rate in pipe at this moment, compare with the level of pure water in same condition.

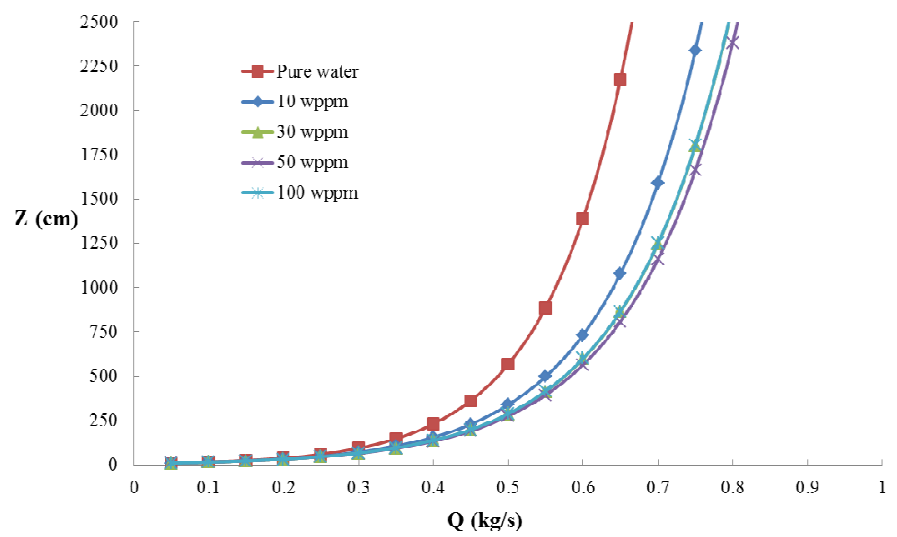

Fig. 6 Relationship between flow rate in pipe and level of water at choking phenomenon. 
From data of this study, when we using polymer solution in difference concentration in pipe flow at turbulent condition, we can increase flow rate in pipe because friction between pipe wall and fluid are decrease follow the hypothesis of Drag reduction effect, in this research can show the data in Fig.7, that is a relationship of friction factor (f) in y-axis and Reynolds number $(\mathrm{Re})$ in $\mathrm{x}$-axis, the result show effect of polymer solution can decrease friction factor immediately by this experiment best of polymer concentration is in 30 to $100 \mathrm{wppm}$ because these friction factor are decrease in closely number compare with pure water, by percentages are 35, 45,44 and $44 \%$ at polymer concentrations are 10,30, 50, $100 \mathrm{wppm}$.

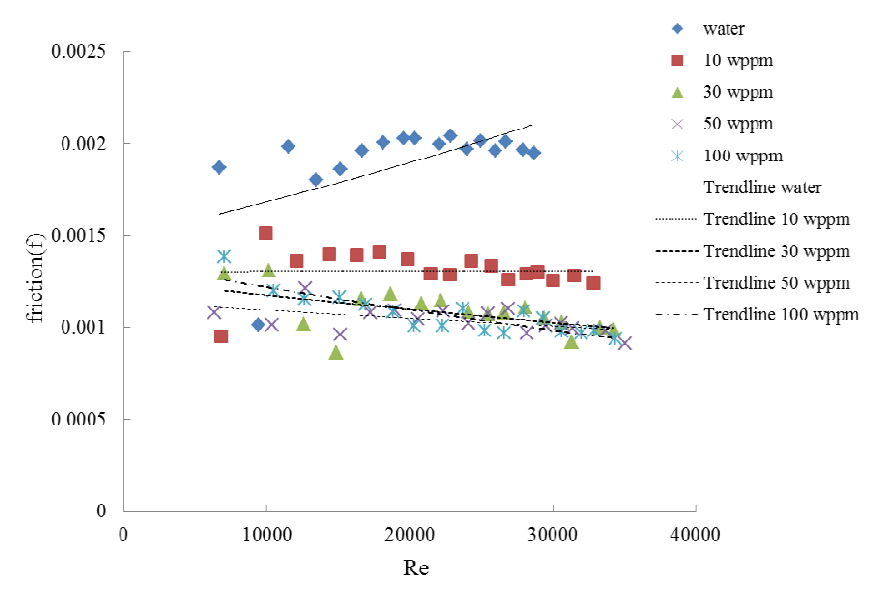

Fig.7 Relationship of friction factor and Reynolds number with and without polymer.

\section{Conclusions}

From the experiments results, the choking phenomenon occurs in pipe systems but can be solved by using polymer at appropriate concentrations in turbulent conditions. The Drag Reduction Effect was observed, and is illustrated in Fig.4, 5 and 7. The flow rate in a pipe can increase due to this Effect of adding polymers. In this study maximum increase enhancement of draining capacity is $13 \%$ and maximum increase flow rate in pipe is $12 \%$ by average.

\section{Acknowledgments}

This study was carried out under the support of the Department of Mechanical Engineering, Faculty of Engineering, Naresuan University, And Assistant Professor Dr. Ananchai Ukeaw for collaboration in this study.

\section{References}

[1] Sattaya Yimprasert, Ananchai Ukaew, Enhancement of Draining Capacity for Over Loaded Sewer During Flooding by Means of Polymer Addition, 7th THAICID NATIONAL SYMPOSIUM, 7 (2012) 56-73.

[2] R.H. Sellin, J.W. Hoyt \& O. Scrivener, The effect of drag reducing additives on fluid flows and their industrial applications, Part 1: Basic aspects. Journal of Hydraulics Research 20 (1982) 29-68.

[3] R.H. Sellin, J.W. Hoyt \& O. Scrivener, The effect of drag reducing additives on fluid flows and their industrial applications, Part 2: Present Application and Future Proposal. Journal of Hydraulics Research, 20 (1982) 236-291. 
[4] C. DERICK and K. LOGIE, Flow augmenting effect of additives on open channel flows, Environmental Protection Agency, Report EPA-R2-73-238, 1973.

[5] R.E. Sojka, D.L. Bjorneberg, J.A.Entry, R.D.Lentzl, W. J. Orts., Polyacrlyamind in agriculture and environmental land management, Advances in Agronomy, 92 (2004) 115-119.

[6] Frank M. White, Fluid Mechanics, 5th ed., Singapore, McGraw-Hill, 2005.

[7] Munson R.B., Fundamental of Fluid Mechanis, New York, John Wiley and Sons, 2006.

[8] Seree Chanyotha, Hydraulic Engineering, Chulalongkorn University, 2010.

[9] Professor Dr. Thongchai Panswad, คู่มือการออกแบบระบบระบายน้ำเสีย และน้ำฝน. สมาคมวิศวกรรมสถานแห่งประเทศไทย ในพระบรมราชูปถัมภ์ และสมาคมวิศวกรสิ่งแวดล้อมไทย, ซีเอ็ดยูเคชั่น. 1996.

[10] M.C. White, M.G. Mungal, Mechanics and Prediction of Turbulent Drag Reduction with Polymer Additives, Annu. Rev. Fluid Mech, 40 (2008) 235-256.

[11] JL. Lumley, Drag reduction by additives, Annu. Rev.Fluid Mech, 1(1969) 367-384.

[12] Professor Dr. Pramote Dechaumphai, Numerical Methods in Engineering, Chulalongkorn University, 1995. 